\title{
Correction to: Taking the EU to Court
}

\section{Correction to:}

C. Adam et al., Taking the EU to Court, Palgrave Studies in European Union Politics, https://doi.org/10.1007/978-3-030-21629-0

The original version of the book was inadvertently published without incorporating the corrections in "Funding details and List of figures" which have been now incorporated. This correction to the book has been updated with the changes.

The updated version of the book can be found at https://doi.org/10.1007/978-3-030-21629-0

(C) The Author(s) 2020

C. Adam et al., Taking the EU to Court, Palgrave Studies in European Union Politics, https://doi.org/10.1007/978-3-030-21629-0_9 